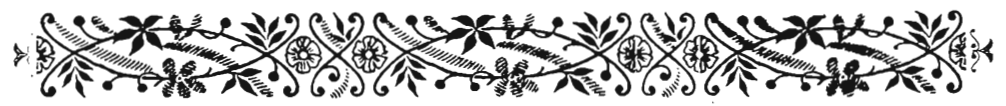

ESCOLA DE COMMERCIO EM S. PAULO

\begin{abstract}
\&O ensino commercial representa no mundo economico o mesmo papel que as escolas de guerra e de marinha no mundo militar; e o problema da expansão commercial é actualmente para todas as nações a questão mais grave, a nota mais vibrante da politica internacional.»
\end{abstract}

Gustavo Penna.

- Nous avons des ingénieurs éminents, des industriels habiles, des ouvriers intelligents et adroits; pour faire connaître leurs produits, pour les écouler sur les marchés lointains, nous n'avons pas as sez de nógociants.

G. Roy.

I. Por estarmos plenamente convencido dos inestimaveis proveitos que, para o Estado de S. Paulo, podem advir da fundação de uma Escola de Commercio, nesta capital, desde 1890 , em que nos confiaram a redacção do "Diario do Commercio», até hoje, sempre temos propugnado pela realisação de tão momen. toso emprehendimento.

Alguns empregados do commercio, certos do nosso empenho, e enthusiastas dessa nobre idéa, em I 897, nos entregaram um projecto que temos em mãos, afim de apresental-o á nossa municipalidade, para que ella tomasse a iniciativa da creação de umá escola de commercio. Com grande pezar não pudemos attendel-os, por conhecer de perto os recursos da camara municipal desta capital, cujas rendas ainda não bastam 
para occorrer a tantos melhoramentos de ordem material, constantemente reclamados por nossa laboriosa população. Hoje, que ganha corpo tão fecunda e generosa idéa já affecta ao Congresso Legislativo do Estado $\left(^{*}\right)$ e, como acreditamos, não está longe de ser, definitivamente, levada a effeito, demonstrando assim que São Paulo não assiste indifferente á transformação radical que se opera no commercio moderno, e cuida de sahir do extraordinario, do incomprehensivel, do injustificavel atrazo em que se encontra relativamente ao importante assumpto - devemos todos contribuir para a prompta e immediata realisação de tão urgente quão notavel commettimento.

II. Com as descobertas e invenções, comı as maravilhosas applicações do vapor e da electricidade, com a admiravel facilidade das communicações entre os povos, e entrelaçamento de seus grandes interesses, operouse uma renovação completa no mundo industrial contemporaneo, bem como no commercio internacional.

Essa evolução assumiu tal importancia que, por toda parte, desperta a reflexão dos governos esclarecidos, obrigando as nações a participarem do movimento progressivo, sob pena de ficar estacionadas na estrada da vida.

E' sabido que o commercio exterior de todas as nações civilisadas, que apenas attingia á uma dezena de milhar de francos, no começo do seculo passado, hoje excede de cem milhares. Esse phenomeno economico tem modificado mais profundamente as condições da sociedade em geral do que as revoluçōes politicas.

(*) Vide o projecto apresentado em sessão de 26 de Abril de r9o I pela commissão de instruç̧ão publica composta dos deputados Fontes Junior, coronel Carlos Porto e Gabriel Prestes e por este fundamentado longamente. Esse projecto, já approvado em segunda discussão, está dependente do parecer da commissão de fazenda. 
E Cohendy e A. Bonner, tratando do assumpto, demonstram, á evidencia, que hoje o commercio não se restringe mais aos limites do territorio de um paiz dado; que as mercadorias extrangeiras fazem concorrencia com as mercadorias nacionaes nos proprios mercados nacionaes, obrigando estes a acceitarem a competencia; que o commercio outr'ora nacional, transformou-se por completo, tornando-se internacional e cosmopolita, de sorte que, por toda parte, se vê uma concorrencia habilmente conduzida, poderosamente organisada, admiravelmente mantida. LÉON SAy. Dicc. d'Ec. Polit. v I, p. 884.

Essa evolução determinou outra, não menos progressiva. A lucta entre os povos, que era outr'ora excepção, tornou-se hoje a regra, constituindo o estado normal das relações internacionaes. Esta lucta não é empenhada á arma branca; ella se trava cada vez mais forte no terreno da producção, no dominio da troca. Embora se a tenha, por antiphrase, qualificado de pacifica, ella é na realidade tão mortifera para os vencidos como os mais sanguinolentos combates. A victoria sempre pertence aos mais preparados, ans mais instruidos.

Fazendo identicas considerações, aquelles escriptores, por nós citados, accrescentam, finalmente, e cle modo positivo a seguinte conclusão:- «L'organisation de l'enseignement technique n'est donc pas une simple quéstion de pédagogie; c'est, au premier chef, une question vitale pour notre pays".

Vivemos em uma epoca de neo-mercantilismo e o principal, senão o unico objectivo da lucta, entre os povos, é, não a vassallagem politica, mas a dependencia economica.

III. A posição do Estado de S. Paulo, relativamente a este ponto, é na verdade, menos lisonjeira ou antes 
pouco animadora. De facto; a classe dos lavradores paulistas desenvolveu tanto a sua iniciativa e actividade que chegou a produzir quasi a metade da exportação brazileira; a classe dos industriaes espalhou, por toda parte, formidaveis usinas, vastas installações executando melhoramentos materiaes de grande monta como o cáes de Santos que, franqueando o nosso principal porto maritimo ao commercio do mundo, representa talvez o mais gigantesco emprehendimento da America do Sul; a classe dos engenheiros estendeu tres mil e quatro centos kilometros de linhas ferreas, proseguindo na construcção de outras tantas neste abençoado solo; a classe dos capitalistas fundou bancos de primeira ordem que tem em suas caixas um lastro permanente de mais de cincoenta mil contos; a classe dos proprietarios levantou ricas e confortaveis vivendas, fazendo, como por encanto, a antiga e academica capital paulista transformar-se em formosissima cidade; a classe dos commerciantes, que tem feito? nada, absolutamente nada!

Consentiu que os extrangeiros se collocassem á frente das principaes casas, tanto do grande como do pequeno commercio, monopolisando já o de alimsentação publica! Sem pessoal habilitado e sufficiente, não tem o commercio paulista quem venda no extrangeiro, o nosso principal artigo de exportação - o café! Espera que o extrangeiro venha compral-o em Santos, e por imposição ou conveniencia de quatro ou cinco casas exportadoras, vê aquelle producto agricola sahir daquelle nosso principal porto de mar, sem a marca da procedencia, sem o nome do mercado de origem!

Percorrendo-se um por um dos estabelecimentos commerciaes desta praça, ter-se-á desagradavel impressão, verificando que na maioria delles, desde o chefe até o mais modesto empregado, quasi todo o pessoal se compõe de extrangeiros, que não teem a obrigação de ser patriotas. 
Observando-se a nossa Associaçâo Commercial e Praça do Commercio, notaremos quasi que a exclusiva frequencia de negociantes extrangeiros. Por outro lado. muitos são os exemplos cle completo successo dos extrangeiros em nosso paiz.

Para não enumeral os todos, basta dizermos que os allemães entraram no Brazil, primeiro como soldados da imperial guarda de Pedro I, subsequentemente pela colonisação, sob o patronato de Pedro II, e hoje rivalisam com os inglezes no sul do Brazil, bem como em S. Paulo, em todas as manifestaçôes do trabalho mercantil.

A que se pode attribuir tamanha falta de elemento nacional. do elemento paulista, em nosso commercio em geral?

Para muitos escriptores patrios, esse mal vem da ausencia de autonomia, vicio organico dos brazileiros. Tavares Bastos, demonstrando esse phenomeno, escreveu:.. O brazileiro não sente-se independente e livre, não dispõe-se a vngar nos mares da vida, contando só com a sina de sua estrella e os ventos de sua fortuna e não se resolve a caminhar senão apoiado n algum braço protector. Nos desertos da existencia não vae elle plantar a arvore que o deve abrigrar; alonga os olhos e procura logo a arvore copada á cuja sombra estende a sua barraca de viagem. "Cartas do Solitario", pag. 9.

Ao nosso ver, a causa principal está primeiro no facto de os governos preocuparem-se mais com o ramo financeiro do que com o commercial; em segundo logar, em ignorarmos a importancia que o commercio assumiu nos tempos modernos, na falta de estimulo á nossa mocidade para abraçar tão nobre carreira, na carencia de institutos de ensino technico, de uma Escola de Commercio!

Em 1900, para obter um criterio embora relativo, dessa falta de estimulo, bem como das vocações in- 
dustriaes ou da preferencia juvenil sobre as differentes profissões, dirigimo-nos á Escola Modelo Caetano de Campos e solicitámos -c procedesse um breve inquerito afim de saber qual a tendencia dos alumnos, acerca deste ou daquelle trabalho social ou occupação humana.

As respostas de 252 alumnos, presentes a nove aulas, habilitaram-nos por uma induç̧ão racional e por uma maneira assás curiosa, a confirmar a necessidade indispensavel de cuidar-se da organisação de nossa sociedade pelo lado economico e pratico.

Verificamos uma inclinação pronunciada para as profissões liberaes, a tendencia commum para o funccionalismo, a crença de que ao Estado, pelo menos até á bancarrota. corre a obrigação de collocar e manter a nossa mocidade quando é certo que um grande numero dos nossos jovens diplomados, naufragam por toda parte, augmentando o numero dos desclassificados.

Dos 252 alumnos inquiridos queriam ser engenheiros 52 , empregados publicos 36 , medicos 32 , advogados 24, guarda-livros 23, professores particulares 21, agricultores I 2, pharmaceuticos 9, negociantes 9, dentistas 7 , padres 6, pintores 4 , maestros 3 , marinheiros 3 , militares 2, mechanicos 2, telegraphistas 2, photographos, carpinteiro, ourives, electricista I sem escôlha I.

Resumindo:- desejavam consagrar-se ás profissões liberaes $64 \%$; ao funccionalismo i $4 \%$ e como a aspiração commum do medico, do engenheiro ou advogado é uma elevada e conveniente collocação na hierarchia administrativa, concluimos que oitenta por cento da população escolar tem como aspiração remota, como ideal, o emprego publico. Nem se diga que seria singular ma. nifestarem os escolares gosto por uma profissão desconhecida e que não se attendeu ao discernimento dos mesmos. O que procuramos foi um criterio approximado para comprovar a necessidade indiscutivel da diffusão do ensino agricola e commercial. 
Foi convencido do atrazu do nosso ensino technico profissional, tanto industrial propriamente dito, como agricola e commercial, que o actual director da Escola Polytechnica, Dr. Paula Souza, em occasião solemne declarou:-- "que aquella Escola, no ponto de vista industrial, vinha reagir contra o nosso deploravel estado de cousas, porquanto o seu objectivo é antes crear cidadãos que saibam executar e praticar do que discorrer e discutir.. Que si tivesse de optar entre uma instrucção meramente scientifica e uma educaçào technica, empirica, preferiria esta ultima». Revista da Esc. Polytechnica, de I900, p. 4I5.

Não foi com diverso pensar que Arago, salientando, em 1830, a insufficiencia do ensino commercial em seu paiz e o abandono que ao mesmo votaram os seus concidadãos, escreveu:- "Ce n'est pas avec de belles paroles qu on fait du sucre de betterave; ce n'est pas avec des alexandrins qu on extrait la soude du sel marin $\bullet$ !

Longe vae portanto a epoca em que CiCERo deixava de nobilitar a profissão commercial, em que MontesQUIEU prohibia a nobreza fazer parte do commercio; em que os reis davam licença para o exercicio de tão util profissão.

O que fica dito não é a reproảuç̧ão de velharias porquanto, em nosso meio, não se tem prestado attenção a taes factos, assim como ao grande papel que o commercio representa na civilisação moderna, e por isso deixa-se de dar á profissão commercial a importancia a que ella tem direito.

Esse preconceito se observa até no seio da familia, onde já um escriptor notou que, não rarı, o chefe diz:-- «Este mell filho, como é o mais intelligente, vae ser advogado e quem sabe mesmo si deputado ou ministro; aquelle por ser mais habil, será engenheiro, aquelle outro, por falta de recursos, irá para o commercio.!

Urge combater tão detestavel preconceito e procla- 
mar a indeclinavel necessidade de ministrar-se o ensino á nossa mocidade, afim de termos, neste Estado, um certo numero de homens habilitados, intelligentes, capazes de lidar no commercio e especialmente no commercio de café, com certo preparo ou sufficientes conhecimentos technicos.

Uma «Escola de Commercio», eis o unico meio talvez de podermos bem preparar a nossa mocidade para esse grande e patriotico desideratum. Esse instituto de ensino habilitará. em poucr; tempo, os nossos jovens a seguirem para as praças extrangeiras, a viverem com vantagens na intimidade dos nossos freguezes, conhecendo-os e comprehendendo-os, obtendo relações e conhecimentos, finalmente a figurarem no commercio exterior em vez de augmentarem o proletariado intellectual ou figurarem na mendicancia do emprego publico!

IV Todas as nações civilisadas, de ha muito, comprehenderam o grande alcance do ensino commercial.

Primeiro foi a Russia, que em 1755 fundou a celebre Escola de São Petersburgo; depois seguiram esse exemplo a Allemanha, creando o instituto commercial de Lubeck, em I793; depois a França, organisando a Escola Superior de Commercio de Pariz, em i 820; e em seguida as demais nações, como a Austria Hungria com a Escola de Praga, a Italia com a Escola de Veneza, a Belgica com a Escola de Anvers, modelo no genero, sendo que hoje em todos esses paizes, mesmo na Inglaterra e Estados Unidos, se encontram numerosos estabelecimentos de ensino commercial e que funccionam regularmente prestando os mais assignalados serviços.

Fazemos este reparo em relação á Inglaterra e Estados Unidos, porque nestes paizes nào existe o ensino superior, propriamente dito. Esta particularidade explica-se facilmente, si se considera o caracter espe- 
cial da raça saxonia. Como fazem notar, muito justamente, Jourdan e Dumont, em sua monographia sobre as escolas de commercio no extrangeiro, na America como na Inglaterra a iniciativa industrial gosa de um grande papel. A maior parte dos hornens que tem conseguido ganhar pé no commercio e na industria deve esta posição a seus esforços pessoaes; tambem são elles geralmente inclinados a que seus filhos sigam seus passos e sejam elles mesmos self made men, isto é filhos de suas proprias obras. Os moços providos de uma instrucção primaria solida e alguns conhecimentos especiaes que lhes são indispensaveis, atiram-se á vida e assim vão aproveitar as lições da pratica para completar a educação e melhorar assim a situação material.

Nos Estados Uniclos, accrescentam Cohendy e Bonnet, é onde o ensino commercial elementar é admiravelmente desenvolvido, e desde muitos annos; os "Business Colleges» e os "Commercial Colleges》 eram em numero de. 26, com 3.800 alumnos, em i 870, e hoje (1895) contam 300 e um effectivo escolar de 50.000. LÉON SAY Dict. cit p 89 I.

$\mathrm{Na}$ Republica Argentina, desde 1892, existem tres importantes estabelecimentos modelos:- $\mathrm{O}$ Instituto Mercantil de Buenos Ayres, a Escola superior do commercio do Rozario e a de Cordoba, tendo aquelle paiz transformado varias escolas normaes em escolas agricolas e de commercio.

No Brazil, excepção feita da Academia de Commercio de Juiz de Fóra, fundada pelo illustre mineiro F Baptista de Olıveira, em via de reorganisação, e da Escula Pratica de Commercio do Pará, que ha tres annos tuncciona com a maior regularidade, não existem outros institutos, sendo isso uma grave lacuna que os poderes publicos devem quanto antes preencher.

A' frente da escola de Minas esteve, por alguns annos, o Dr. Gustavo Penna que, elogiando a sua organisação, em I 5 de Agosto de 1897, escreveu:- 
"Creio piamente que nenhum estabelecimento de ensino superior em nosso paiz offerece mais largo horisonte á nobre ambição da mocidade do que a Academia de Commercio. De posse de seu diploma, tão honroso como qualquer outro e que representa um solido preparo intellectual, o novo academico si pretende seguir uma carreira publica, pode disputar com vantagem qualquer posto, certo de que, si é amigo de seu paiz, poderá servil-o dignamente.»

$\mathrm{V}$ Tratando-se da organisação do ensino, devemos primeiramente ter em linha de conta a grande conveniencia de começarmos pela fundação de Escolas Praticas ou de r. "gráo, cujo fim é um rudimentar preparo intellectual dos moços para o commercio, isto é, a formação de soldados para o exercito do commercio.

Só depois de organisado o ensino elementar por assim dizer, é que devemos cuidar das Escolas Superiores ou de 2. ${ }^{0}$ gráo, destinadas a formar os bons patrões ou generaes, que ainda com o ensino sempre se habilitam, de modo definitivo, na lucta da concorrencia que é o campo de batalha do commercio!

$\mathrm{O}$ que vem de ser exposto se nos afigura como um ponto fundamental, donde não devemos desviar a attenção por isso que é notoria, em nosso meio, a falta quasi absoluta de moços habilitados para os escriptorios, para a faina diaria da compra e venda, de pagar e receber, de notar e registrar cuidadosamente as operações mercantis.

O "Paulista ", orgam do importante Gremio dos Guarda-Livros de São Paulo, em editorial de 15 de Junho do anno passado, sob a epigraphe-Escola de Commercio - explanou com lucidez esse ponto, mostrando quanto é delicado e complexo esse acto de auferir com intelligencia e discernimento, um justo lucro entre 
as operaçठ̃es da compra e venda e a cujo desconhecimento attribue a causa de muitoś insuccessos na vida real. O estudo referido, da lavra do snr. H. Berlinck, professor da nossa Escola Polytechnica, merece ser lido.

A nossa observação tem ainda em seu apoio, além da opinião de Cohendy E Bonnet, a de um escriptor autorizado na materia, MARCEL BICHon, que, a proposito, escreveu bellos artigos no "Économiste Fransais" de 6 e 20 de Maio de I 899, onde estabeleceu aquella hierarchia natural no ensino commercial que tambem adoptamos.

Em que pése ás opiniões de Léactey, Couriot e Siegfried, partidarios do ensino em tres gráos, nós não devemos nos esforçar senão pelo estabelecimento de duas categorias de interessados, aos quaes se possa ministrar o ensino commercial-a dos patrões de um lado e a dos empregados de outro, preferindo sempre estes, em tudo e por tudo.

A inferioridade cue se nota no ensino commercial da França, em relação aos demais paizes, é devida ao facto de primeiro ter-se alli cuidado do ensino superiol com a fundaçào da Escola de Pariz, em i 820, e desdenhar-se do ensino elementar só divulgado após a lei de I I de Dezembro de i880.(*)

Quanto ao ponto de vista escolar ou de programma de ensino, pouco diremos por faltar-nos conhecimento

(*) No projecto da Universidade que acaba de apresentar ao illustre Ministro do Interior, Dr. Sabino Barroso, o operoso lente jubilado desta Faculdade, Conselheiro Leoncio de Carvalho, indicou um plano para o funccionamento de uma Academia de Commercio destinada aos que pretendem habilitar-se para o exercicio de consulados, directores de bancos, companhias e estabelecimentos mercantis. O ensino foi dividido por quatro annos e não nos parece obedecer ao intuito exclusivamente pratico. Como se vê pelo art. 447, para a matricula na Academia de Commercio exige-se certificado de approvação, conferida pelo Gymnasio Nacional, gymnasios estadoaes ou particulares a elle equiparados dos seguintes preparatorios:-portuguez, francez, inglez, allemão, mathematica elementar, geographia, especialmente do Brazil, physica e chimica geral, estudo concreto, historia natural, estudo concreto, e desenho linear.

- Na Escola Pratica de Commercio do Pará o plano adoptado é diverso do que se projecta e bem satisfatorio.

Para a matricula no primeiro anno, é necessario instruir a petigão, diri- 


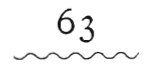

especial da materia. Todavia parece-nos ser conveniente somente admitir-se alumnos maiores de i 5 annos e a organisação de um curso de tres annos apenas, observando se a seguinte distribuição de materias:

\section{0 ANNO}

Linguas, nacional, franceza, ingleza ou allemã. Exercicios oraes)

Mathematicas. Arithmetica, elementos de algebra e geometria.

Contabilidade. Noções geraes de escripturação mercantil.

\section{2. ${ }^{\circ}$ ANNO}

Linguas, nacional, franceza, inģleza, ou allemã (Exercicios oraes).

Contabilidade commercial e financeira. Stenographia e desenho.

b) Technologia ou estudo geral de mercadorias. Conhecimento da composição physica e chimica das mercadorias, sua proveniencia, valor e processos pelos quaes se pode conhecer a sua falsificação ou alteração.

gida ao director da escola, com attestados de ser o candidato vaccinado, de não soffrer de molestia contagiosa e de ter feito exame de instrucção primaria. Faltando este ultimo documento, o candidato fica sujeito a exame prévio, perante a congregação da escola.

$*_{*}^{*}$ O ensino pratico e theorico do estabelecimento acha-se dividido em facultativo e integral.

- No curso facultativo, é concedida aos alumnos a matricula em qualquer das disciplinas, tendo em vista facultar, não importa a quem, mas especialmente aos empregados no commercio, a acquisição de conhecimentos uteis á profissão mercantil.

- No curso integral, o ensino é methodico e obrigatorio e constituirá habilitação sufficiente para o cargo de guarla-livros, de que se dará diploma e outros empregos do commercio.

$\mathrm{O} \mathrm{I}^{\circ}$ anno do curso comprehende o estudo de mathematicas, linguas por. tugueza e ingleza, calligraphia, stenographia e dactylographia e geographia commercial e historia do commercio.

O $2 .^{\circ}$ anno consta de continuação da $1 .^{a}$ parte das mathematicas, escripturação mercantil, mercadorias, linguas franceza, ingleza e allemã.

$\mathrm{O} 3 .^{\circ}$ anno abrange o estudo de mathematica superior, direito commer- 


\section{$3 \cdot{ }^{\circ}$ ANNO}

Geographia Economica e Commercial. Productos de cada paiz e mercados. Producção brazileira. O café. Historia do commercio e tratados de commercio.

c)

Legislafão. Regra geraes de direito. Legislação commercial, industrial e maritima, com especialidade a aduaneira e de fallencias.

- Economia Politica e Finanfas. Estatistica. Systemas monetarios; operações de bolsa e de bancos.

E' certo que grande parte do successo depende muitas vezes da aprendizagem pratica. Essa, porém, só se adquire na lucta da concorrencia nos estabelecimentos mercantis, nas praças de commercio. Esse tirocinio completará a educação commercial, como as lides forenses em relação ao advogado e a clinica em relação aos medicos e os trabalhos industriaes em relação ao engenheiro.

VI. Expostas estas ideias geraes sobre o programma a seguir, cumpre reconhecer a grande influencia dos professores a quem fôr commettida a tarefa de ministrar o ensino. A proposito, escreveu Guizor:- —As melhores leis, as melhores instituições, os melhores programmas nada valem quando aquelles que são incumbidos de os traduzir em realidade, nâo são inteira-

cial e economia politica, contabilidade, lingua portugueza, e pratica das linguas franceza, ingleza e allemã

$O$ estudo das linguas extrangeiras no $\mathbf{I}^{\circ}$ e $2 .^{\circ}$ anno é o mais pratico possivel e tendente ao seu objecto final: isto é, que os exercicios de leitura, traducção e versões sejam de preferencia relativos a assumptos commerciaes e com emprego da technologia commercial.

No $3{ }^{\circ}$ anno se faz a synthese, sendo as licções alternadas em umas e outras linguas, fazendo-se applicação ás especialidades profissionaes do que se apprender nos dois primeiros.

Como se vê a Escola de Commercio do Pará só tem por objectivo um ensino assás generico, assás preciso e pratico, el'enseignement court s na phrase simples e expressiva do ministro Hanotaux. Le Fournal, de 18 de Novembro de 1901 . 
mente devotados, não tem o coração tocado de sua missão E' Eobretudo homens encarregados de ensinar que convém formar.».

Recommendar um rigoroso escrupulo na escolha dos professores ou na organisação do corpo docente de um instituto da ordem do que se trata-é de toda conveniencia.

Concluidas as nossas ligeiras observaçoes diremos,assim como F. C. Search (*), que, lamentando não terem os americanos uma só instituição bancaria na America do Sul, appellou para um trabalho continuo, persistente e pessoal no intuito de obter-se a expansão do commercio exterior bancario do seu paiz, tão avantajado nesta parte do continente, pela concorrencia ingleza e allemã,- da mesma forma devemos appellar para identico esforço patriotico, para uma acção decisiva, continua e obstinada da proverbial iniciativa paulista, afim de crear-se uma «Escola de Commercio em S. Paulo», como o complemento da instrucção agricola, já admiravelmente organisada, e como o ponto de partida da nossa expansão commercial.

\section{Dr. Veiga Filho}

S. Paulo, I9 de Dezembro de Igor.

(*) North American Review, de Março de 1899 .

-Depois de concluido este artigo recebemos do exmo. sr. Dr. Gabriel Piza, ministro do Brazil em Pariz, os programmas e mais informações acerca das principaes Escolas de Commercio da Europa e que conservamos á disposição de quem melhor queira estudar o assumpto.

Deixamos de aprecial-os neste trabalho, porque isso importaria na modificação do plano adoptado... Demais, falta-nos tempo para um largo e conveniente exame da interessante questão. 